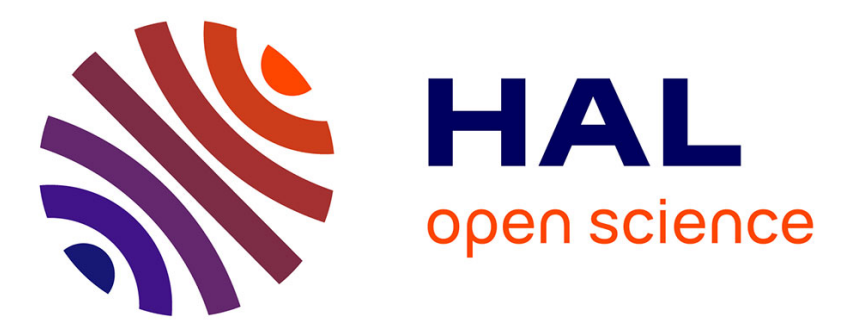

\title{
Influence of chelating agents on the photopolymerization of hybrid Ti-based waveguides
}

Xavier Le Guével, Christian Palazzesi, Paolo Prosposito, Gioia Della Giustina, Giovanna Brusatin

\section{- To cite this version:}

Xavier Le Guével, Christian Palazzesi, Paolo Prosposito, Gioia Della Giustina, Giovanna Brusatin. Influence of chelating agents on the photopolymerization of hybrid Ti-based waveguides. Journal of Materials Chemistry, 2008, 18 (30), pp.3556. 10.1039/b802257g . hal-02337802

\section{HAL Id: hal-02337802 https://hal.science/hal-02337802}

Submitted on 8 Nov 2019

HAL is a multi-disciplinary open access archive for the deposit and dissemination of scientific research documents, whether they are published or not. The documents may come from teaching and research institutions in France or abroad, or from public or private research centers.
L'archive ouverte pluridisciplinaire HAL, est destinée au dépôt et à la diffusion de documents scientifiques de niveau recherche, publiés ou non, émanant des établissements d'enseignement et de recherche français ou étrangers, des laboratoires publics ou privés. 


\title{
Influence of chelating agents on the photopolymerization of hybrid Ti-based waveguides
}

\author{
Xavier Le Guével, ${ }^{a}$ Christian Palazzesi, ${ }^{a}$ Paolo Prosposito, ${ }^{* a}$ Gioia Della Giustina ${ }^{b}$ and Giovanna Brusatin ${ }^{b}$ \\ Received 8th February 2008, Accepted 16th May 2008 \\ First published as an Advance Article on the web 20th June 2008 \\ DOI: $10.1039 / \mathrm{b802257g}$
}

Sol-gel derived inorganic-organic hybrid materials (HYBRIMERs) have shown a great potential for planar and channel waveguides due to their high photosensitivity, low-cost processing and good suitability for doping. These materials have been synthesized with a high content of titanium ( $40 \%)$ and with three different chelating agents: acetylacetone, methacrylic acid and trifluoroacetic acid. The degree of photopolymerization of the methacrylate part changes with the nature of the chelating agent. Trifluoroacetic acid and methacrylic acid are the chelating agents showing the highest photopolymerization conversion. All coatings were crack free (thickness $\sim 1 \mu \mathrm{m}$ ), transparent in the visible spectra range with refractive indexes from 1.54 to 1.58 . Simple confined structures based on trifluoroacetic acid with well-defined shapes, smooth surfaces $(\mathrm{RMS}=0.28 \mathrm{~nm})$ and good optical properties were synthesized. Straight and bent channel waveguides and beam splitters were patterned by UV exposure and wet etching, and light confinement effects into the different channel waveguides were shown.

\section{Introduction}

HYBRIMERs were developed and studied in a wide field of electronic and photonic applications because of their excellent optical properties and relatively high thermal stabilities in comparison to optical polymers. ${ }^{1-6}$ The presence of organic components increases the flexibility of the sol-gel network preventing its cracking, allows low consolidation temperatures, and opens the possibility to combine the attractive features of organic polymers with those of silicate networks at a molecular level. Such properties are of particular interest in the area of optical waveguide materials notably with their photocurability. ${ }^{7-10}$ First organic-inorganic three dimensional (3D) waveguides were developed by Krug et al. and Najafi et al. ${ }^{11,12}$ More recently, thanks to the process simplicity and the high optical performance, the number of researchers working on these materials has considerably increased..$^{13-18}$

Photo-curable HYBRIMERs are synthesized through the introduction of photosensitive precursors, which usually contain $\mathrm{C}=\mathrm{C}$ bonds such as unsaturated hydrocarbon or epoxide substituents. ${ }^{14,19-24}$ Many studies have been reported on hybrid materials based on different inorganic networks ( $\mathrm{Si}, \mathrm{Zr}$, Ti, etc.) and on different photosensitive precursors.

In our case, the hybrid photopolymerizable material was composed of methacrylate and silicate/titania networks and a commercial photinitiator (Irgacure 184-CIBA). We have chosen such systems since acrylic groups typically have high multiphoton photopolymerization yields. As a result the UV curing has the effect of inducing photopolymerization of the methacrylate species and at the same time it increases the silica

${ }^{a}$ Dipartimento di Fisica, Università di Roma-Tor Vergata and INSTM, Via della Ricerca Scientifica 1, 00133 Rome, Italy.E-mail: prosposito@ roma2.infn.it

${ }^{b}$ Dipartimento di Ingegneria Meccanica, Università di Padova and INSTM, Via Marzolo 9, 35131 Padova, Italy network condensation. In general it has been found that the oxygen has a fundamental role in the photopolymerization of hybrid sol-gel materials. ${ }^{21,25}$ Moreover, titania was incorporated into the silica network in order to increase its refractive index. ${ }^{26,27}$ We used a high content of titania to produce films with refractive indexes of the order of $1.54-1.58$ at $640 \mathrm{~nm}$. However, the high concentration of titanium can deteriorate the optical properties of the hybrid matrix and complicate the synthesis process, due to the faster hydrolysis reaction kinetics of such a precursor compared to a silica one ${ }^{16,27,28}$ and the strong absorption of this metal under UV exposure. ${ }^{29}$ In this regard the presence of chelating agents which reduce the hydrolysis reaction by screening and preserving titanium molecules is of great importance.

The aim of this work is to understand if the nature of the complexing agent has an impact on the optical properties of planar and channel waveguides realized with methacrylic hybrid materials. To this purpose, we have synthesized different HYBRIMERs with three chelating agents of the titanium precursor: acetylacetone (Acac), methacrylic acid (MAA) and trifluoroacetic acid (TFA). The use of TFA as a chelating agent is rather new in hybrid sol-gel materials, even if recently Bartl et $a l^{30,31}$ have shown the lasing properties of a dye-doped hybrid waveguide with trifluoroacetate-modified titania networks. The molar proportion of titanium with respect to silicon was fixed to $40 \%$ and to our knowledge there are no other publications on the synthesis of hybrid materials with such a high titanium content. We compared the effect of MAA and Acac, which are the most commonly used chelating agents of Ti alkoxides, with TFA which is an acid with strong electron-withdrawing groups ${ }^{32}$ and therefore it could strongly reduce the high reactivity of titanium.

Structural investigations and photopolymerization degrees have been investigated by Fourier transform infrared spectroscopy (FTIR) measurements. Optical and surface properties have been checked before and after UV irradiation onto planar 
waveguides by UV-VIS absorption, spectroscopic ellipsometry characterization and atomic force microscopy (AFM) analysis. Finally, simple confined structures based on TFA with well-defined shapes and good optical properties were fabricated. In particular, straight and bent channel waveguides and beam splitters have been patterned by wet etching demonstrating a good light confinement effect into the different channel waveguides.

\section{Experimental}

\section{Chemical synthesis}

Hybrid materials were synthesized using 3-(trimethoxysilyl)propyl methacrylate $98 \mathrm{wt} \%$ (TMSPM) and titanium propoxide $\left[\mathrm{Ti}(\mathrm{OPr})_{4}, 98 \mathrm{wt} \%\right]$ as precursors. Three different types of chelating agents have been selected to protect the titanium during the polymerization: acetylacetone $>99.5 \mathrm{wt} \%$, methacrylic acid $99 \mathrm{wt} \%$ and trifluoroacetic acid $99 \mathrm{wt} \%$. All the chemical products have been purchased from Sigma-Aldrich and have been used without further purification. The structures of the precursors and chelating agents are shown in Scheme 1. TMSPM, diluted in isopropanol, was first prehydrolyzed with acidic water $(0.01 \mathrm{M} \mathrm{HCl})$ in a water/TMSPM ratio 0.75 and stirred for $1 \mathrm{~h}$. Three sols have been prepared by adding chelating agents to complex titanium(Iv) propoxide with the molar ratio ChelAg: $\mathrm{Ti}=4: 1$ and stirring for $20 \mathrm{~min}$. This ratio was chosen in order to stabilize the titanium alkoxide. Afterwards, the prehydrolyzed TMSPM was mixed to the three chelated complexes of titanium. Isopropanol and water were added allowing to obtain the molar ratio Ti : TMSPM : ChelAg: $\mathrm{H}_{2} \mathrm{O}$ : isopropanol $=1: 1.5: 4: 2: 12$ for all sols. Irgacure 184 (CIBA) was added to the sols $\left(4 \mathrm{wt}^{\%} \%\right)$ to promote the photopolymerization. Then, the mixtures were stirred in the dark for $30 \mathrm{~min}$ and left at room temperature for $16 \mathrm{~h}$.

The nature of the photoinitiator has an impact on the structure and the absorbance of the materials. ${ }^{25,33-35}$ We used Irgacure 184 because of its high photosensitivity in the wavelength range 300$400 \mathrm{~nm}$. Furthermore the internal filtering is low and is welladapted for square planar waveguides. ${ }^{33}$ The chemical reaction is a free radical polymerization. A monomer or oligomer joins with a free radical and forms a larger free radical. This larger free radical then acts upon another monomer or oligomer and forms

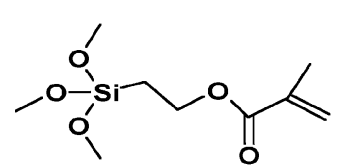

TMSPM

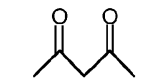

Acetylacetonate (Acac)
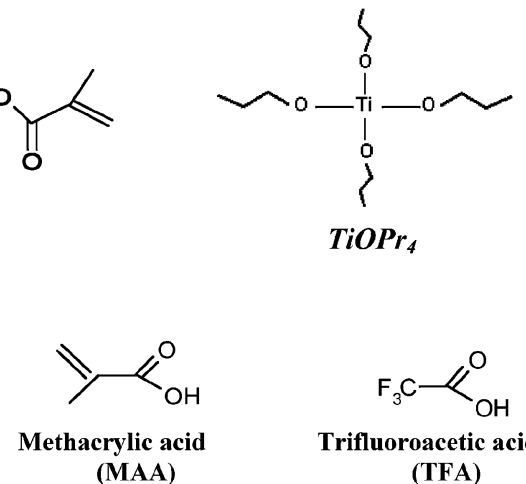

Scheme 1 Molecular structure of precursors and chelating agents used in the hybrid film synthesis. an even larger molecule, and so on. The process is a chain reaction that is endless until a polymer molecule is terminated. We have chosen a photoinitiator concentration in agreement with previous work in the range $1-5 \mathrm{wt} \%$ in solution. A stronger concentration could be a drawback because it would decrease the optical quality of the films both for its dispersion and its potential contribution to the absorption loss at $1550 \mathrm{~nm}$ (absorption of the $\mathrm{C}-\mathrm{H}$ groups).

\section{Film deposition and characterization}

Sols Ti-TMSPM with Acac, MAA and TFA have been filtered using membranes of $0.2 \mu \mathrm{m}$ porosity and deposited by spincoating at $3000 \mathrm{rpm}$ onto glass substrates and silicon wafers. All substrates were preliminarily cleaned using an acetone bath in an ultrasound vessel and then rinsed with deionized water. After deposition, films were prebaked at $80{ }^{\circ} \mathrm{C}$ for $30 \mathrm{~min}$ to remove residual solvents. Two series of coatings were prepared. The first one had been irradiated using an UV XeHg lamp $(\lambda=280 \mathrm{~nm}-$ $400 \mathrm{~nm}$ ) with a power density of $160 \mathrm{~mW} \mathrm{~cm}^{-2}$ for 1 min to promote the polymerization of the methacrylate groups. The second was stored without light irradiation under dark conditions at room temperature. Finally, the two series of Ti-TMSPM coatings, exposed and unexposed, with three different chelating agents were postbaked at $80{ }^{\circ} \mathrm{C}$ for $2 \mathrm{~h}$. All the coatings, both irradiated and non-irradiated by UV light have been subsequently characterized by different techniques. Absorption spectra were collected using an UV-visible spectrophotometer Perkin-Elmer $\lambda 15$ in the range $200-900 \mathrm{~nm}$. The refractive indexes and thicknesses of the films were measured using a Variable Angle Spectroscopic Ellipsometer (VASE® by J.A. Woollam Co.). Structural information such as the condensation of the inorganic network and the degree of the photopolymerization of the methacrylate part have been determined by FTIR measurements using films deposited onto silicon wafers. Infrared absorption spectra in the range $4500-400 \mathrm{~cm}^{-1}$ were recorded using a PerkinElmer 200 set-up with a resolution of $1 \mathrm{~cm}^{-1}$.

\section{Channel waveguide fabrication}

Planar waveguides of Ti-TMSPM with different chelating agents were deposited on silicon substrates having a thick layer of silicon oxide $(8 \mu \mathrm{m})$. The films were prebaked at $80^{\circ} \mathrm{C}$ for $30 \mathrm{~min}$ and subsequently were exposed to UV light $(\lambda=280 \mathrm{~nm}-400 \mathrm{~nm})$ for 1 min through a metallic mask grown on a quartz substrate having the desired pattern. The prebaking process was necessary since the coatings are too sticky so they cannot be patterned by contact with a photomask. Three chemical reactions happened at the same time during the UV irradiation: the organic polymerization of the methacrylate species, the condensation of the inorganic network (matrix Silica-Titania) and the evaporation of alcohol and water.

After irradiation, films were immersed in pure isopropanol for 2 min to develop channel waveguides removing the unexposed part. The UV exposure time and the period of development are two parameters to select together carefully in order to realize the best structure with a well-defined rectangular shape and a smooth surface. After the development, the patterned structures were postbaked at $80{ }^{\circ} \mathrm{C}$ for $2 \mathrm{~h}$ to definitely stabilize the 
system by the enhancement of the mineral network. Indeed, a postbaking process is quite common in order to consolidate the structure achieved by UV exposition and complete the polymerization process.

The morphology and roughness of channel waveguides have been measured by AFM (Veeco Technology) in tapping mode. The structures were observed using both an optical microscope and a scanning electron microscope (SEM). The waveguide properties were tested by coupling a light at $514 \mathrm{~nm}$ from an $\mathrm{Ar}^{+}$ laser by means of a single mode fiber to the confined structures.

\section{Results and discussion}

\section{Planar structures}

The UV-VIS transmittance spectra of films prepared with the three chelating agents before and after UV exposure are shown in Fig. 1. Independent of the chelating agent, all coatings are transparent in the visible range $400-700 \mathrm{~nm}$. The strong absorption band at $280 \mathrm{~nm}$ visible in all the spectra is due to the presence of titanium. The big shoulder between 300 and $400 \mathrm{~nm}$ for Ti-TMSPM with Acac coating (Fig. 1a) corresponds to the absorption of the complex Ti-Acac. ${ }^{36}$ For all the coatings the effect of light exposition is a decrease in the transmittance in the range $320-450 \mathrm{~nm}$, probably due to possible formation of absorbing species related to the organic part of the network upon irradiation.

Spectroscopic ellipsometric measurements were accomplished in the spectral range $400-1000 \mathrm{~nm}$ for all the films before and after irradiation. Refractive index dispersion curves for the three chelating agents before and after UV irradiation are shown in Fig. 2. Before UV exposure, refractive indexes of coatings based on MAA and Acac are similar, as reported in Table 1 for $\lambda=$ $640 \mathrm{~nm}$. On the contrary, the refractive indexes of the TFA based films are lower compared with the other chelating agents. This effect can be related to the presence of a fluorine compound in the coating. ${ }^{37}$ TFA has indeed $n=1.30$ compared to the higher refractive indexes of Acac (1.45) and MAA (1.43) and the high
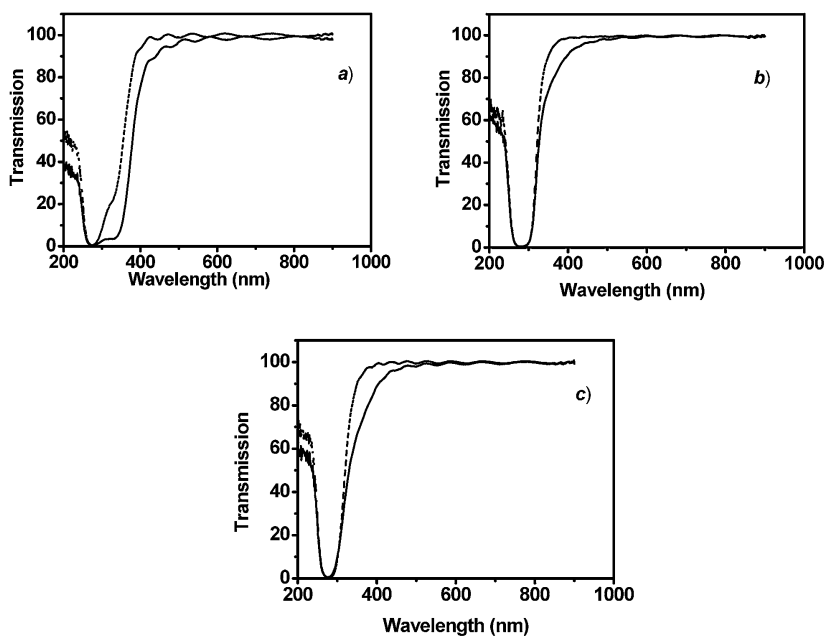

Fig. 1 Transmission measurements of the three planar coatings with (a) Acac, (b) MAA and (c) TFA before (dashed curve) and after (solid line curve) UV irradiation at $160 \mathrm{~mW} \mathrm{~cm}{ }^{-2}$ for $1 \mathrm{~min}$.
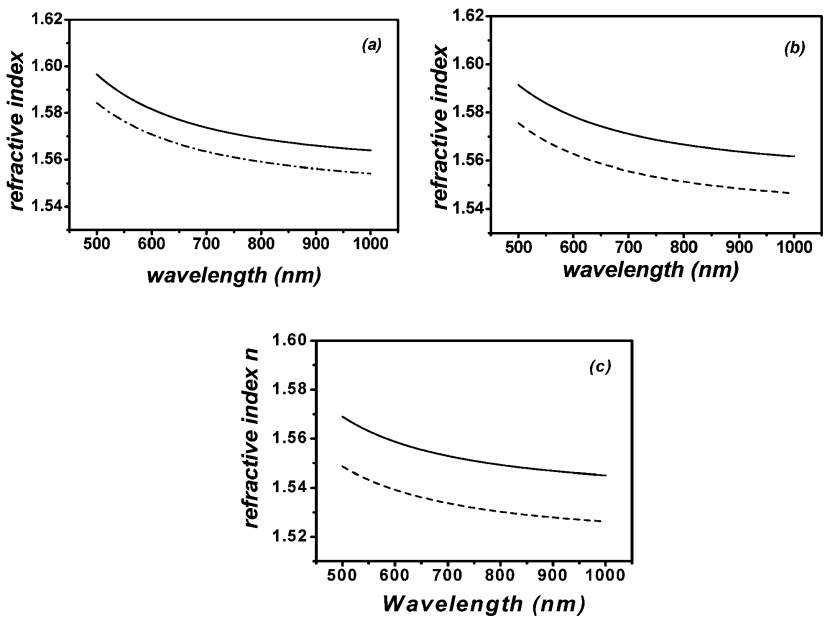

Fig. 2 Refractive index as obtained by spectroscopic ellispometry of coatings on silicon substrates for the 3 different chelating agents before (dashed curve) and after (solid curve) UV irradiation. (a) Acac, (b) MAA and (c) TFA.

Table 1 Refractive index at $\lambda=640 \mathrm{~nm}$ of planar waveguides before and after UV exposure as a function of the different chelating agents. The difference between the exposed and unexposed refractive indexes is reported in the last line

\begin{tabular}{lrrr}
\hline & Acac & MAA & \multicolumn{1}{l}{ TFA } \\
& $n$ & $n$ & $n$ \\
\hline Without UV & 1.567 & 1.559 & 1.537 \\
With UV & 1.578 & 1.575 & 1.556 \\
$\Delta n$ & +0.011 & +0.016 & +0.019 \\
\hline
\end{tabular}

amount of chelating agent present in the coating (molar ratio $\mathrm{Ti}$ : Chel. Agent $=1: 4$ ) can explain such a consistent difference. The thickness before irradiation for all the coatings was around $1.1 \mu \mathrm{m}$ independent of the chelating agents. After UV irradiation a small variation in the thickness has been detected (in the range $5-10 \%$ ) and an increase in the refractive index was found for the three coatings. Differences in the refractive indexes between exposed and unexposed films are reported in Table 1.

FTIR spectra of samples Ti-TMSPM with different chelating agents are quite similar as shown in Fig. 3 where the spectral interval $1000-2000 \mathrm{~cm}^{-1}$ is reported. Absorption band centered at $1720 \mathrm{~cm}^{-1}$ is assigned to the $\mathrm{C}=\mathrm{O}$ stretch of the methacrylate group. The characteristic vibration of the $\mathrm{C}=\mathrm{C}$ bounds of the

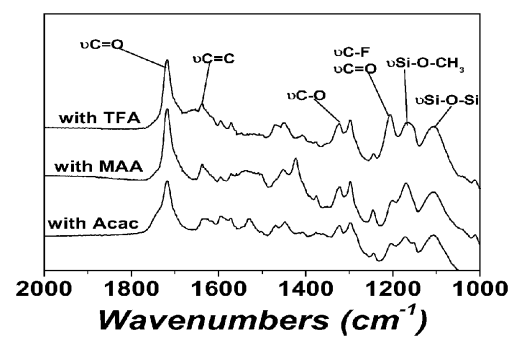

Fig. 3 Infrared spectra of coatings with Acac, MAA and TFA as chelating agents. 
methacrylate group are located at $1637 \mathrm{~cm}^{-1}$. The bands around $1400-1600 \mathrm{~cm}^{-1}$ could be attributed to $v(\mathrm{C}-\mathrm{O})$ and $\mathrm{v}(\mathrm{C}-\mathrm{C})$ vibrations of the chelating agents (Acac, MAA and TFA) bonded to the titanium. In particular, when complex Ti-Acac is formed three carbonyl vibrations (at $1620 \mathrm{~cm}^{-1}$ and the doublet peaks at $1708 \mathrm{~cm}^{-1}$ and $1728 \mathrm{~cm}^{-1}$ typical of the enol tautomeric Acac) disappear and two new bands are generated at $1580 \mathrm{~cm}^{-1}$ and $1530 \mathrm{~cm}^{-1} .^{38}$ In Fig. 3 the different features of the Ti-Acac spectrum in the region $1770-1600 \mathrm{~cm}^{-1}$ with respect to those observed for Ti-TFA and Ti-MMA, suggest that not all the Acac forms a chelating complex, and it is present in the enol tautomeric form in the unirradiated film. This behavior is common in the presence of water and with high amounts of Acac with respect to Ti precursor. In fact, in our system, Ti-Acac, the ratio Acac/Ti is 4/1. Moreover, a shoulder at $1740 \mathrm{~cm}^{-1}$ and a broad band at $1630 \mathrm{~cm}^{-1}$ are visible in Fig. 3, probably due to the overlap of the enol tautomeric Acac $\mathrm{C}=\mathrm{O}$ absorptions at 1730 and $1620 \mathrm{~cm}^{-1}$ with the $\mathrm{C}=\mathrm{C}$ bond absorptions of the methacrylate group at 1720 and $1637 \mathrm{~cm}^{-1}$.

Peaks at 1245 and $1167 \mathrm{~cm}^{-1}$ correspond to the $\mathrm{CH}$ symmetric stretching vibrations bonded to silicon and methoxy groups $\mathrm{Si}-\mathrm{O}-\mathrm{CH}_{3}$ of the organosilane TMSPM respectively. The presence of these residual methoxy groups indicates an incomplete polymerization of the inorganic network during the synthesis. This behavior could be related to the high content of titanium which promotes a fast reaction rate. We also note a most intense band at $1200 \mathrm{~cm}^{-1}$ for the coating with TFA, certainly due to an overlap of the bands corresponding to the $\mathrm{C}-\mathrm{F}$ vibration onto the carbonyl bond. The broad band at $1100 \mathrm{~cm}^{-1}$ is related to the $\mathrm{Si}-\mathrm{O}-\mathrm{Si}$ asymetric bond stretching.

The behavior of each coating before and after UV exposure is reported in Fig. 4. After UV exposure, a decrease and a shift of the carbonyl bond from 1720 to $1730 \mathrm{~cm}^{-1}$ can be observed for all samples, and for Ti-Acac an increase of the bands related to the chelating complex is also observed, probably due to the elimination of residual water. As noted by several authors ${ }^{2,21,34}$, the carbonyl bond was shifted after $\mathrm{UV}$ irradiation because $\mathrm{C}=\mathrm{O}$ is no longer conjugated with a vinyl constituent. The intensity of
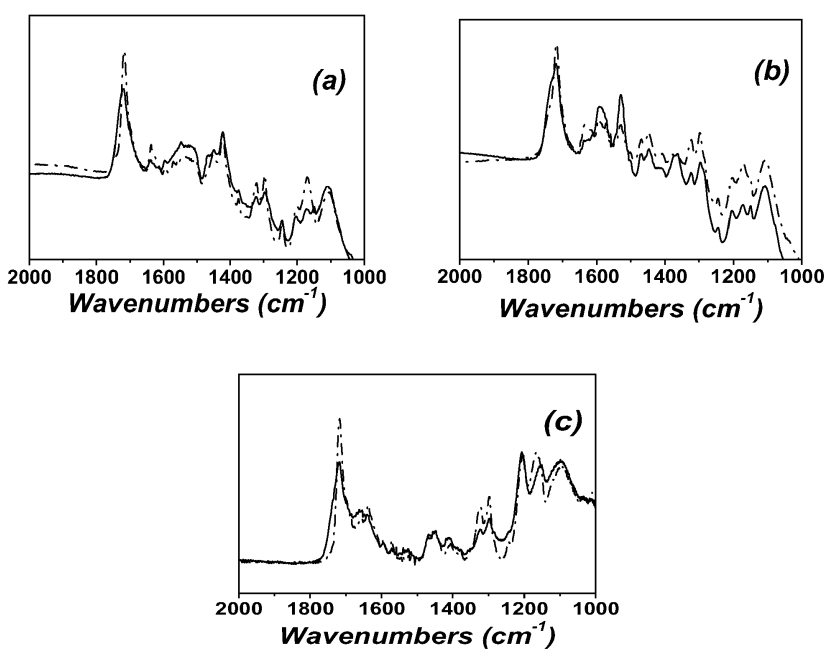

Fig. 4 Infrared spectra of Ti-TMSPM coatings with Acac (a), MAA (b), and TFA (c) as chelating agents before (dashed curve) and after (solid curve) UV irradiation.
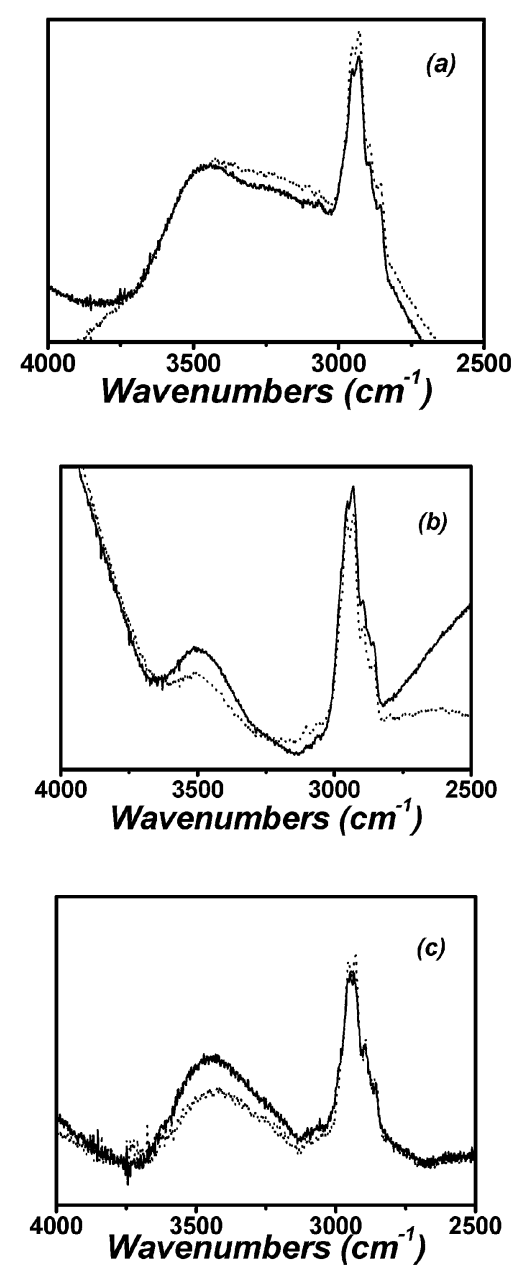

Fig. 5 Infrared spectra of Ti-TMSPM coatings with Acac (a), MAA (b), and TFA (c) as chelating agents before (dashed curve) and after (solid curve) UV irradiation.

the peak of the $\mathrm{C}=\mathrm{C}$ group stretching mode at $1637 \mathrm{~cm}^{-1}$ decreases with UV exposure for all coatings. This indicates that the photopolymerization of methacrylate groups begins after light exposition. Furthermore, as illustrated in Fig. 5, the spectra of the different coatings show no real modification of the peaks at $2900 \mathrm{~cm}^{-1}$ which are related to the $\mathrm{C}-\mathrm{H}$ vibration of the organic part. This means that the methacrylate content in the hybrid material is probably quite similar between all samples. From all these considerations we can make a semi-quantitative comparison for the 3 chelating agents to determine the conversion degree ${ }^{20,23}$ of the $\mathrm{C}=\mathrm{C}$ group using the following formula:

$$
C=\frac{A_{0}-A_{\mathrm{t}}}{A_{0}}
$$

where $A_{0}$ and $A_{\mathrm{t}}$ are the area under the peak $\mathrm{C}=\mathrm{C}$ at $1637 \mathrm{~cm}^{-1}$ before and after UV exposure for $1 \mathrm{~min}$ at $160 \mathrm{~mW} \mathrm{~cm}{ }^{-2}$. The estimated degree of photopolymerization is about $78 \%, 60 \%$ and $71 \%$ for Acac, MAA and TFA, respectively, with a possible excess on the estimation for Acac due to the contribution of the enol tautomeric Acac form. For this reason we decided to consider another reference peak for the methacrylate absorbtion. ${ }^{39}$ In particular the peak at $1325 \mathrm{~cm}^{-1}$ can be considered. In 
Table 2 Conversion degree of the $\mathrm{C}=\mathrm{C}$ group before and after $\mathrm{UV}$ exposure considering absorption at $1637 \mathrm{~cm}^{-1}$

\begin{tabular}{llll}
\hline Coatings Ti-TMSPM & Before & After & $\% \mathrm{C}$ \\
\hline With Acac & 0.67 & 0.15 & 78 \\
With MAA & 1.05 & 0.42 & 60 \\
With TFA & 0.69 & 0.20 & 71 \\
\hline
\end{tabular}

Table 3 Conversion degree of the $\mathrm{C}=\mathrm{C}$ group before and after UV exposure considering absorption at $1325 \mathrm{~cm}^{-1}$

\begin{tabular}{llll}
\hline Coatings Ti-TMSPM & Before & After & $\% \mathrm{C}$ \\
\hline With Acac & 0.39 & 0.22 & 44 \\
With MAA & 0.64 & 0.23 & 64 \\
With TFA & 0.70 & 0.26 & 63 \\
\hline
\end{tabular}

this case the degree of photopolymerization is $44 \%, 64 \%$ and $63 \%$ for Acac, MAA and TFA, respectively. All results are gathered in Table 2 and 3. These data show that the polymerization of the methacrylate part depends on the chelating agent used. In particular, the data regarding Acac based films are in disagreement if the peak at 1637 or that at $1325 \mathrm{~cm}^{-1}$ are considered. In this regard we are more confident on the result obtained by considering the absorption band at $1325 \mathrm{~cm}^{-1}$ since the contribution of the enol tautomeric Acac form can alter the real value of the polymerization degree. Our supposition is also supported by the correlation between the refractive index variation before and after UV exposure. Ti-TFA and Ti-MAA coatings having a high degree of polymerization also show an intense variation in refractive index before and after UV irradiation, while Ti-Acac films having a small difference in refractive indexes before and after light exposition present the lowest degree of organic polymerization.

From FTIR analysis (Fig. 4 and 5), we can observe a decrease in the band at $1167 \mathrm{~cm}^{-1}$ after UV exposure for all coatings corresponding to the degradation of the residual alkoxide involving the formation of silanol groups and a correspondent increase in the absorption due to the $\mathrm{OH}$ groups at $3400 \mathrm{~cm}^{-1}$. This last feature is particularly evident for TFA and MMA systems, while in Acac films the residual methoxy, if present, and the inorganic part seem not to be influenced by the UV irradiation.

The UV irradiation produces an increase in the absorption at $3480 \mathrm{~cm}^{-1}$ that can be assigned to $\mathrm{Si}-\mathrm{OH}$ but also $\mathrm{C}-\mathrm{OH}$, and a decrease in the absorption at 940 (Ti-MMA and Ti-TFA) and $960 \mathrm{~cm}^{-1}$ (Ti-AcAc), due to Si-OH only. Therefore, it is possible to conclude that an inorganic condensation also occurs during UV irradiation.

Summarizing, both ellipsometric and FTIR measurements prove that UV irradiation promotes a consistent polymerization of the methacrylate part. In particular, a higher organic conversion rate has been found for TFA and MAA based coatings compared to the Acac based films.

\section{Confined structures}

Photopolymerizable resins and hybrid organic-inorganic materials are often used to fabricate buried channel waveguides. ${ }^{40}$
Sometimes the change in refractive index, given by the UV exposure and postbake treatment, is sufficient to confine the light and therefore channel waveguides can be easily made up by photochemical self-developing without using a further chemical developing process.

As reported in Fig. 2 the difference in the refractive index of our systems based on Acac, MAA and TFA as chelating agents is of the order of $\Delta n=0.01-0.02$ which is enough to reach the 2-dimensional optical confinement ${ }^{41}$ also without any developing step. Nevertheless, the solubility in some solvents of the unexposed part of these materials can also be exploited to realize patterned structures by wet etching. We used a development process based on a bath of isopropanol to remove the unexposed regions followed by a postbaking process. Ridge-channel waveguides have been fabricated using Ti-TMSPM with the three different chelating agents. However, in this paper we report briefly only on the surface and optical characterization of channel waveguides realized with TFA. The overall optical study of other patterned structures fabricated by wet etching and direct writing based on Acac and MAA hybrid materials will be the subject of a forthcoming paper.

Parameters such as the surface roughness and the steepness of the sidewalls of the channel waveguides are very important because they can greatly affect the optical performance of the structure. Fig. 6 shows well-defined sidewalls with a smooth surface $(\mathrm{RMS}=0.28 \mathrm{~nm}$ ) in the exposed and unexposed regions indicating the good optical quality of the material. Different simple patterns have been obtained by UV illumination of the coating through a metallic mask. The widths of the strip channel waveguides were in the range 2-16 $\mu \mathrm{m}$ while the lengths were of the order of $2-3 \mathrm{~cm}$. The thickness of the structures was around $1.2-2 \mu \mathrm{m}$ indicating a complete polymerization of the planar coating. The realization of channel waveguides was not easy, mainly due to the high $\mathrm{Ti}$ content $(40 \% \mathrm{Ti})$ which is very sensitive to UV irradiation. Moreover, we noticed that the final hybrid structures had a larger width compared to the mask apertures. This behavior can be explained by the non perfect contact between the mask and the film surface in the UV irradiation

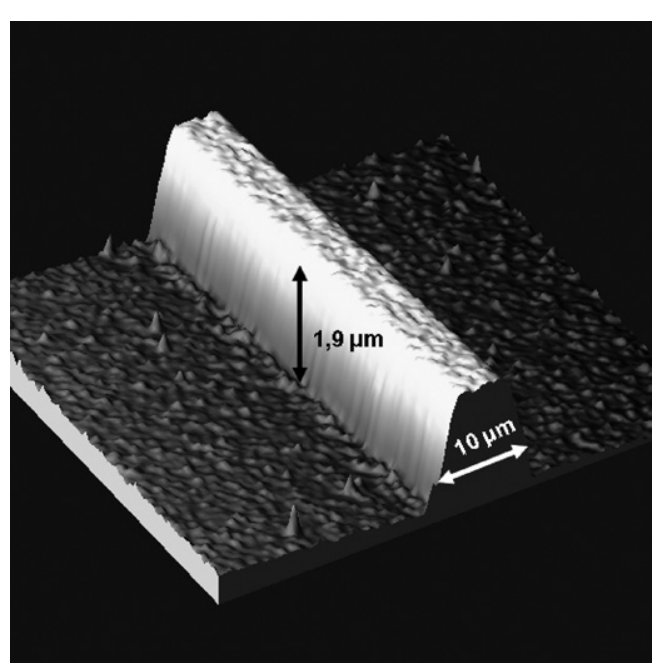

Fig. 6 AFM measurement of a strip waveguide fabricated by wet etching from a coating Ti-TMSPM with TFA. 

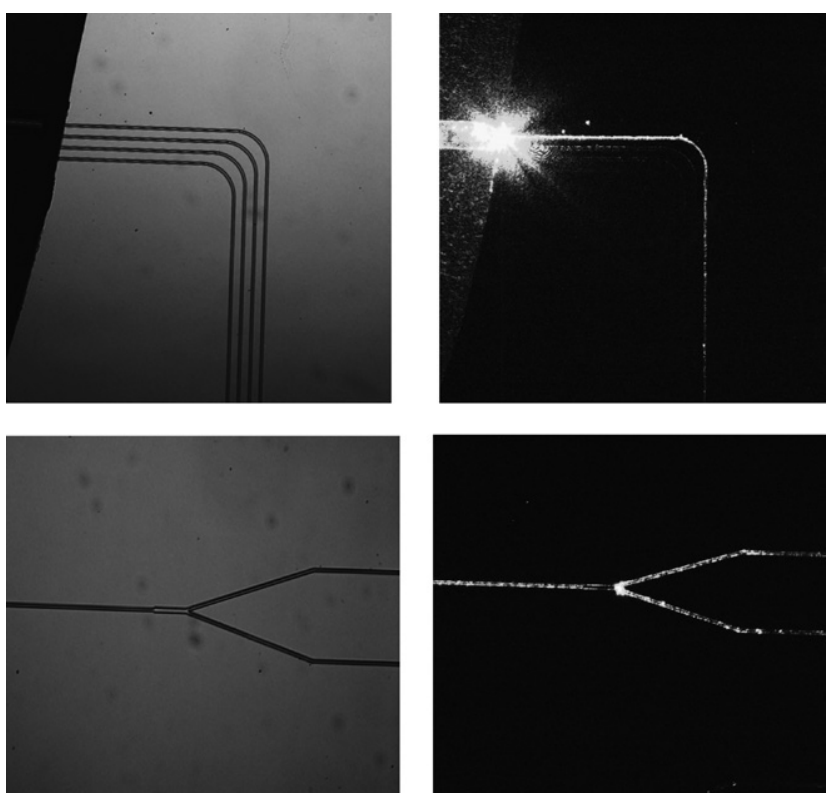

Fig. 7 Optical microscope pictures of a Y-beam splitter and bent channel waveguides made by Ti-TMSPM with TFA as a chelating agent. On the right, insertion of a laser light $(514 \mathrm{~nm})$ by a single mode optical fiber into the same structures showing the good optical confinement.

procedure since we used a home made exposure system instead of a commercial mask aligner. The poor contact could increase the light diffraction effect at the edges, causing an enlargement of the patterned structures.

However, the definition of the patterning is definitely good and we realized confined waveguides up to $2 \mu \mathrm{m}$ width having different shapes as shown in Fig. 7 where two different examples, Y-beam splitter and bent waveguides are reported. The relative light confinement into these channels is also shown in the same figure using a laser light at $514 \mathrm{~nm}$ launched into the structure by a single mode optical fiber.

\section{Conclusion}

We synthesized sol-gel derived organic-inorganic waveguides based on titanium precursors with a high titanium content $(40 \%)$ using different chelating agents: acetylacetonate, methacrylic acid and trifluoroacetic acid. The nature of the chelating agent has an impact on the polymerization degree of the organic moiety for the hybrid material. FTIR study and ellipsometric characterization revealed that Ti-TFA and Ti-MAA coatings present a high degree of polymerization (around 64\%) and at the same time they also show an intense variation of the refractive index before and after UV irradiation $(\Delta n=0.016-0019)$, while $\mathrm{Ti}-$ Acac films have a low degree of organic polymerization $(44 \%)$ and present a low difference in the refractive index before and after light exposition $(\Delta n=0.011)$. Well-defined channel waveguides have been fabricated using Ti-TFA hybrid sol-gel material by a wet etching process. The high confinement of light in such structures demonstrates the great interest for this type of material for many photonics applications such as micro ring optical resonators, electro-optic modulators and optoelectronics devices.

\section{Acknowledgements}

The authors gratefully acknowledge the FIRB Italian project RBNE033 KMA "Molecular compounds and hybrid nanostructured materials with resonant and non resonant optical properties for photonic devices" for financial support and Dr Enrico Orsini for AFM characterization.

\section{References}

1 Sol-gel optics II, ed. J. D. Mackenzie, Proc. SPIE-Int. Soc. Opt. Eng., 1992, vol. 1758.

2 K. Saravanamuttu and M. P. Andrews, Chem. Mater., 2003, 15, 14.

3 T. Suratwala, Z. Gardlund, K. Davidson and D. R. Uhlmann, Chem. Mater., 1998, 10, 199.

4 M. Feuillade, C. Croutxe-Barghorn and C. Carre, Prog. Solid State Chem., 2006, 34, 87-94.

5 U. Schubert, E. Arpac, W. Glaubitt, A. Helmerich and C. Chau, Chem. Mater., 1992, 4, 291-295.

6 V. Uricanu, D. Donescu, A. G. Banu, S. Serban, M. Olteanu and M. Dudau, Mater. Chem. Phys., 2004, 85, 120-130.

7 N. Yamada, I. Yoshinaga and S. Katayama, J. Appl. Phys., 1999, 85, 2423-2427.

8 D. Blanc and S. Pelissier, Thin Solid Films, 2001, 384, 251-253.

9 B. S. Bae, J. Sol-Gel Sci. Technol., 2004, 31, 309-315.

10 H. Yiang, X. Yuan, Z. Yun, Y.-C. Chan and Y.-L. Lam, Mater. Sci. Eng., C, 2001, 16, 99-102.

11 H. Krug, F. Tiefensee, P. W. Oliveira and H. Schmidt, Sol-gel optics II, Proc. SPIE-Int. Soc. Opt. Eng., 1992, 1758, 448-455.

12 S. I. Najafi, C. Y. Li, M. Andrews, J. Grisham, P. Lefebvre, J. D. Mackenzie and N. Peyghambarian, Functional Photonic Integrated Circuits, San Jose, Proc. SPIE-Int. Soc. Opt. Eng., 1995, 2401, 110-115

13 Z. Xiao, L. Haijing, A. Soutar and Z. Xianting, Proc. Electron. Packag. Technol. Conf. 5th, 2003, 2003, 744.

14 P. J. Moreira, P. V. S. Marques and A. P. Leite, IEE Photonics Technology Letters, 2005, 17, 399-401.

15 J. I. Jung, O. H. Park and B. S. Bae, J. Sol-Gel Sci. Technol., 2003, 26, 897.

16 X. Luo, C. Zha and B. Luther-Davies, J. Sol-Gel Sci. Technol., 2004, 32, 297-301.

17 P. Ayras, J. T. Rantala, R. Levy, M. R. Descour, S. Honkanen and N. Peyghambarian, Thin Solid Films, 1999, 352, 9-12.

18 B. Wang and L. Hu, Ceram. Int., 2006, 32, 7.

19 S. O’Brien, R. J. Winfield, A. Connell and G. M. Crean, Mater. Res. Soc. Symp. Proc., 2005, 847, EE 13.20.1.

20 Y. J. Eo, J. H. Kim, J. H. Ko and B. S. Bae, J. Mater. Res., 2005, 20, 401 .

21 O. Soppera, C. Croutxe-Barghorn, C. Carre and D. Blanc, Appl. Surf. Sci., 2002, 186, 91-99.

22 D. Blanc, S. Pelissier, P. Y. Jurine, O. Soppera, C. Croutxe-Barghorn and C. Carre, J. Sol-Gel Sci. Technol., 2003, 27, 215-220.

23 J. Franc, D. Blanc, A. Zerroukhi, Y. Chalamet, A. Last and N. Destouches, Mater. Sci. Eng., B, 2006, 129, 180-185.

24 J. Zhang, S. Luo and L. Gui, J. Mater. Sci., 1997, 32, 1469-1472.

25 O. Soppera and C. Croutxe'-Barghorn, J. Polym. Sci., Part A, 2003, 41, 831-840.

26 M. Yoshida and P. N. Prasad, Chem. Mater., 1996, 8, 235-241.

27 F. Del Monte, P. Chebben, C. P. Grover and J. D. Mackenzie, J. Sol-Gel Sci. Technol., 1999, 15, 73-85.

28 Y. Matsuura, S. Miura, H. Naito, H. Inoue and K. Matsukawa, J. Organomet. Chem., 2003, 685, 230-234.

29 X. C. Yuan, W. X. Yu, W. C. Cheong and N. Q. Ngo, J. Phys. D: Appl. Phys., 2002, 35, L81-L84.

30 S. W. Boettcher, M. H. Bartl, J. G. Hu and G. Stucky, J. Am. Chem. Soc., 2005, 127, 9721-9730.

31 M. H. Bartl, S. H. Boettcher, E. L. Hu and G. D. Stucky, J. Am. Chem. Soc., 2004, 126, 10826-10827.

32 J. C. Yu, W. Ho, J. Yu, S. K. Hark and K. Iu, Langmuir, 2003, 19, 3889-3896.

33 M. Oubaha, P. Etienne, S. Calas, R. Sempere, J. M. Nedelec and Y. Moreau, J. Non-Cryst. Solids, 2005, 351, 2122-2128. 
34 S. Costacurta, L. Malfatti and P. Innocenzi, J. Sol-Gel Sci. Technol., $2007,44,59-64$.

35 J. H. Moona, Y. G. Shula and H. T. Kimb, Int. J. Adhes. Adhes., 2005, 25, 301-312.

36 S. Coussan, Y. Ferro, A. Trivella, M. Rajzmann, P. Roubin, R. Wieckzorek, C. Manca, P. Piecuch, K. Kowalski, M. Wloch, S. A. Kucharski and M. Musial, J. Phys. Chem. A, 2006, 110, 39203926.

37 Dong Jun Kang, Tae-Ho Lee and Byeong-Soo Bae, J. Sol-Gel Sci. Technol., 2004, 31, 113-116.
38 A. L'eaustic, F. Babonneau and J. Livage, Chem. Mater., 1989, 1, 240; H. J. Chen, L. Wang and W. Y. Chiu, Mater. Chem. Phys., 2007, 101, 12-19.

39 M. Langlet, M. Trejo-Valdez, O. Soppera and C. Croutxè-Barghorn, Thin Solid Films, 2005, 472, 253-260.

40 Amir Fardad, Mark Andrews, Galina Milova, Ali Malek-Tabrizi and Iraj Najafi, Appl. Opt., 1998, 37, 12.

41 G. Brusatin, G. Della Giustina, M. Guglielmi, M. Casalboni, P. Prosposito, S. Schutzmann and G. Roma, Mater. Sci. Eng., C, 2007, 27, 1022-1025. 